\title{
Water Quality Parameter Monitoring System Using Low Power Wide Area Network Technology (LPWAN) and Internet of Things (IOT)
}

\author{
Sebastián Retes Cálix, Bachelor of Engineering in Mechatronics ${ }^{1}$, Rigoberto Castro Castro, Master in Dynamics of \\ Machines and Systems ${ }^{2}$ \\ ${ }^{1}$ Universidad Tecnológica Centroamericana (UNITEC), Honduras, sebastian.retes@unitec.edu \\ ${ }^{2}$ Universidad Tecnológica Centroamericana (UNITEC), Honduras, rigoberto.castro@unitec.edu.hn
}

\begin{abstract}
Access to drinking water has been one of the basic needs of the human being, in addition to being considered a fundamental human right. The measurement, analysis and control in real time and remotely of the parameters that determine whether it is suitable for human consumption has meant a need in water purification systems in rural areas of difficult access. The project has focused on the development of a system for measuring water parameters that guarantee the safety of its consumption, these data are the potential of hydrogen $(\mathrm{pH})$, reduction-oxidation potential (ORP) and parts per million of chlorine residual in water. This system uses an intelligent interface for data transmission in conjunction with the Internet of Things (IOT). The parameters measured in the water are identified as fundamental for the determination of the quality of water suitable for human use, thereby promoting food security in the Central American region. The project has proposed the integration of low cost technologies, low energy consumption, internet of things and long range communication technologies. It was determined that Low Power Wide Area Network (LPWAN) technology and LoRa devices meet the necessary requirements for the execution of the system, in addition, The Things Network platform was used to visualize real-time water parameters and cloud storage. The project presents an innovative proposal for its implementation in rural communities that have water purification systems, with this, it is sought to have greater control and effective management of water purification systems to improve the food security in rural communities of difficult access.

Keywords-Water Quality, Water Parameters, Monitoring System, Water Purification System, Low Power Wide Area Network Technology (LPWAN), Internet of Things (IOT), Rural communities.
\end{abstract}

\section{INTRODUCTION}

Drinking water is a vital resource for human survival, however, there is a great problem around its consumption. It is estimated that 2,100 million people lack access to safe managed drinking water services [1]. In every country there are governmental and non-governmental programs and organizations whose purpose is to assist rural communities with limited resources to carry out measurement and correction actions in the treatment of water for consumption.

Digital Object Identifier (DOI):

http://dx.doi.org/10.18687/LACCEI2020.1.1.59

ISBN: 978-958-52071-4-1 ISSN: 2414-6390
However, in many communities these actions are not achieved on time due to problems of availability of expert technicians and difficult access by means of communication to certain communities. These inconveniences cause serious health problems in the inhabitants who consume this water, since it may not be suitable for consumption and thus generate diseases and epidemics.

Currently, in developing countries there is no intelligent system for monitoring water quality parameters in storage and distribution tanks for drinking water. With the development of an intelligent monitoring system, these variables in the water can be monitored efficiently and in a timely manner, obtaining accurate and real-time data. The creation of an electronic system that can measure water quality parameters represents an efficient solution to be applicable in developing countries [1].

This paper describes the design and development of an intelligent system with low cost and low energy consumption for the measurement and transmission of water parameters using LPWAN technology and LoRa devices. Finally, IOT is integrated to access this data remotely, which seeks to make sound decisions about the correct management of drinking water systems.

This system presents an innovative proposal to improve drinking water treatment systems in communities with limited resources and difficult access. The system provides intelligent control in the management of water treatment for human consumption, thereby considerably reducing the outbreak of diseases and epidemics generated by the consumption of water not properly treated.

\section{INSTRUMENTATION AND SOFTWARE}

The instrumentation and engineering software used to develop the project are detailed.

\section{A. Software}

Radio Mobile: used to perform the theoretical mapping of the coverage area that the monitoring system will have.

Ubiquiti AirLink: used to calculate link performance expectations, shows the first fresnel zone and indicates the signal strength in the operating zone.

Google Earth: used to visualize digital maps of the work area, also contains information on the geography of the

$1^{\text {th }}$ LACCEI International Multi-Conference for Engineering, Education, and Technology: "Engineering,

Integration, And Alliances for A Sustainable Development", 27-31 July 2020, Virtual Edition. 
terrain to check the line of sight between the sending and receiving antenna.

Arduino IDE: allows the compilation, creation and editing of codes with the .ino extension on an Arduino card.

Raspbian: operating system used in the Raspberry Pi. It allows the configuration of the card, the integration of libraries necessary to enable the operation of external components and the compilation of codes.

Notepad ++: used for editing codes in multiple formats. The applicability of programming languages such as $\mathrm{C}, \mathrm{C}++$, Phyton and Java is necessary for its applicability.

ProfiCAD: is a tool for creating electrical diagrams.

B. Instrumentation

The proposed system consists of several components, which are in continuous monitoring of water quality. The main components are the measurement sensors, gateway, nodes and power supply system, each component is detailed below:

RAK 831 module: it was used as a system gateway, receives the signal from the node and sends it to the server. Includes converter board that works as a direct means of physical connection between the RAK 831 and Raspberry Pi Zero W.

Raspberry Pi Zero W: was used as the gateway controller.

8GB microSD memory: Raspbian Lite operating system for Raspberry Pi Zero W was installed.

Arduino LoRa Shield version 1.4: it was used as a system node, it sends the information to the gateway via radio frequency.

Arduino Uno: it was used as a LoRa Shield controller and was used to interpret the sensor signals.

Sensor CL-7600: system responsible for measuring PPM of residual chlorine, including the measuring probe, its flow cell and its controller.

PH / ORP-280 sensor: responsible for measuring $\mathrm{pH}$ or ORP. Its corresponding measuring probe and its controller are included.

Flow cell: tank where the water sample is temporarily stored so that the sensors measure the water quality variables.

$12 \mathrm{~V}$ and $20 \mathrm{aH}$ deep cycle rechargeable battery Hykolity brand: power supply of the measurement systems, being $24 \mathrm{VDC}$ powered systems, two batteries were used in series to reach the required voltage.

$24 \mathrm{~V}$ and $30 \mathrm{~W}$ Aleko solar panel and controller kit: used as a charging system for the batteries of the measurement systems.

$3.2 \mathrm{~V}$ and $800 \mathrm{mAh} \mathrm{LiFePO} 4$ rechargeable battery, Eastar brand: Arduino Uno and LoRa Shield power supply, as these are devices that require a 5.0 VDC to 12.0 VDC power supply, two batteries will be used in series to reach the required voltage.

Current to voltage converter module: converts the current output of the $0-20 \mathrm{~mA}$ sensors to a signal from 0.0 to $5.0 \mathrm{~V}$ in a proportional and linear manner, so that the Arduino Uno can interpret the signal correctly.

\section{Methodology}

\section{A. Project implementation area}

In order to develop the project, it was necessary to determine potable water treatment and storage systems in which the implementation of an intelligent remote monitoring system was necessary. Three drinking water systems were identified in the department of La Paz, Honduras. These are the San Rafael, El Chiflador and El Manzanal system with capacities of 70000, 150000 and 33000 gallons of water, respectively. According to documents of the Regulatory Body of Drinking Water and Sanitation Services (ERSAPS) in Honduras, 3315 homes are connected to the water system of the urban area of Marcala, La Paz [4].

TABLE I

\begin{tabular}{|c|c|c|c|}
\hline $\begin{array}{c}\text { Total } \\
\text { Housing }\end{array}$ & $\begin{array}{c}\text { Water Management } \\
\text { Boards }\end{array}$ & $\begin{array}{c}\text { Homes with } \\
\text { drinking water }\end{array}$ & $\begin{array}{c}\text { Housing without } \\
\text { drinking water }\end{array}$ \\
\hline 3,463 & 993 & 3,315 & 148 \\
\hline
\end{tabular}

The National Statistics Institute (INE) in a population projection in 2019 , indicates that a total of 14,115 people live in these three communities [5].

\section{B. Water data Monitoring Module (Sensors)}

Given that the technical guide on sanitation, water and health, microorganisms are totally eliminated with a value of $0.5 \mathrm{ppm}$ of residual chlorine. In this way, it was decided that a residual chlorine ppm measurement system will be implemented for the storage tank in the Chiflador. In the San Rafael and El Manzanal storage tanks, $\mathrm{pH}$ level and ORP level measurement systems were used. According to regulations of the International Standards for Drinking Water and WHO data, a constant ORP value of $650 \mathrm{mV}$ and a $\mathrm{pH}$ that is between 6.5 and 8 units, it can be considered that the water is disinfected and suitable for human consumption.

Sensors were selected based on the requirements of the parameters to be measured in the water. In addition, it was taken into account that they must provide a constant measurement and with the least requirement of corrective maintenance.

Due to the parameters of the measurement and geographic location of the tanks, a monitoring system with the following requirements was sought:

- Few human intervention for data measurement

- Few maintenance

- Easy installation

- Measuring range within the parameters required by international health standards

- Acquisition of data automatically and continuously

$1^{\text {th }}$ LACCEI International Multi-Conference for Engineering, Education, and Technology: "Engineering, Integration, And Alliances for A Sustainable Development", 29-31 July 2020, Buenos Aires, Argentina. 
- No need to add reagents to take measurements

- Digital measurements with current output signal

- Powered by batteries

- Protection against adverse environmental conditions

- Good cost-benefit ratio

The operating process of the parameter monitoring module in water is detailed in the diagram in Fig. 1.

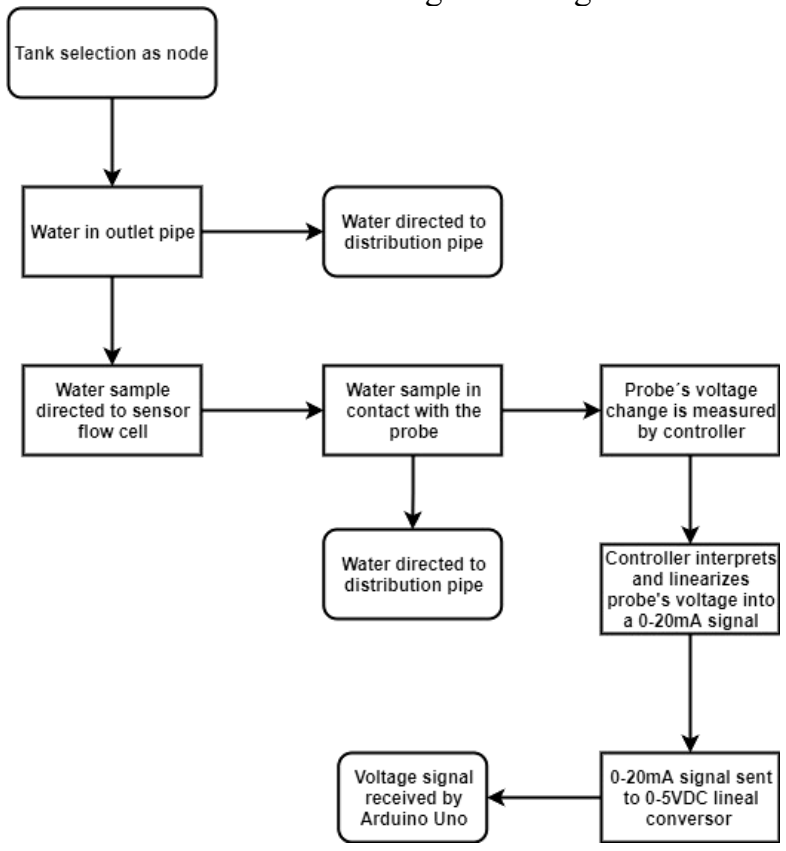

Fig. 1 Operation Diagram of Monitoring Module

For the storage tank at El Chiflador, it was decided to use a CL-7600 measurement system from Nanning Nobo Instrument $\mathrm{Co}$, since it met all the established requirements.

For the storage tanks in San Rafael and El Manzanal it was determined that the installation of a $\mathrm{pH}$ level sensor and an ORP level sensor for each tank was the most convenient. So it was decided to implement the PH-280 and ORP-280 systems of Nanning Nobo Instrument Co.

\section{Communication module}

The project required the design of a system that communicates the data obtained by the sensors wirelessly, using the lowest possible energy consumption, using a radio frequency link; no need for internet, from the node (the storage tank) to the signal receiving gateway located in a central area of the geographical area of operation.

The technology that meets all the requirements is the LPWAN, the products developed with this technology transmit data through the ISM bands, and these bands are open license worldwide and allow the transfer of regulated data. The National Telecommunications Commission in Honduras (CONATEL) mentions that the ISM radio frequency bands used in Honduras are in the range of 902$928 \mathrm{MHz}$ in Region 2 (central frequency $915 \mathrm{MHz}$ ) [2].
There are several implementations of the LPWAN protocol, such as NB-IoT, Sigfox, RPMA, Weightless and LoRaWAN, to name a few. It was decided to use LoRaWAN and LoRa as a communication protocol and as a physical layer respectively. The communication system has three main elements: a server, gateway and node.

For the server, it was decided to use The Things Network; this presents a support platform to the community and offers the data management servers, it is here that the nodes and gateways have to be connected. Likewise, here the equipment is registered, it is also where the information and the keys that are subsequently necessary for the access to the data are provided.

The operation of the communication module can be defined at the diagram in Fig. 2.

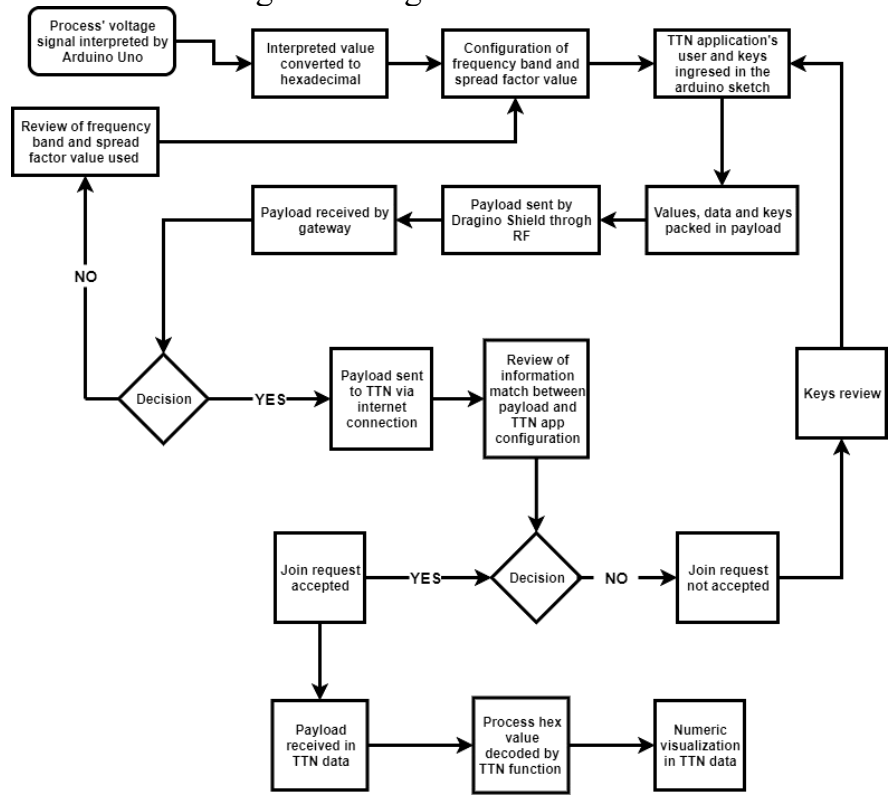

Fig. 2 Diagram of operation of communication system

TTN has a usage policy, it only allows 30 seconds of uplink time per node. The uplink time per message varies depending on the propagation factor (SF) used in the node (the higher the SF, a greater transmission range will be obtained, but the transmission will increase its time in the air), for a payload of 10 bytes, the number of messages allowed is translated into the 20 messages per day with an SF of 12 and 500 messages per day with an SF of 7 [10].

There is the possibility of simplifying the messages, thus reducing the payload load and increasing the amount of messages that can be sent. Following the guidance of the TTN usage policy, it can be deduced that 648 messages can be sent per day in the storage tank node in El Chiflador and about 600 messages for the San Rafael and El Manzanal nodes.

For a constant measurement, it was decided to send a message every 10 minutes, which means a total of 144 messages per day with an SF of 7, this per node.

$1^{\text {th }}$ LACCEI International Multi-Conference for Engineering, Education, and Technology: "Engineering, Integration, 
For the nodes, it was decided to use a Dragino Shield version 1.4 and an Arduino Uno as its controller. With the use of these components it was possible to highlight their very low cost and low energy consumption.

\section{Energization Module}

The calculation of the gateway power was not relevant, since the system will have an electric current available 24 hours a day. However, it is essential to have a $5 \mathrm{VDC}$ and $2 \mathrm{~A}$ constant power supply for proper operation. The three sensors have an average consumption of between 3 and 5 Watts each, their power supply is $24 \mathrm{VDC}$, and it was decided to use two $12 \mathrm{VDC}$ batteries in series with a capacity of $20 \mathrm{Ah}$. It was necessary to include in the design the installation of a solar panel to keep the measurement system running constantly.

It was decided to use a $24 \mathrm{~V}$ and $30 \mathrm{~W}$ solar power system, which conforms to the design requirements. Simplified diagrams of the node, gateway and sensors respectively can be seen in Figs. 3, 4 and 5.

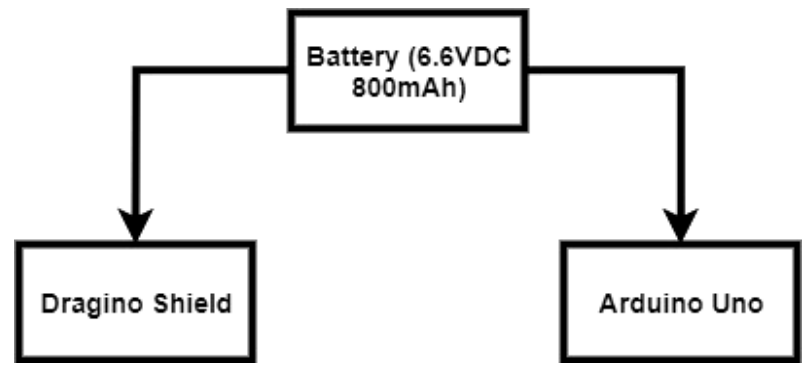

Fig. 3 Node Energization Diagram

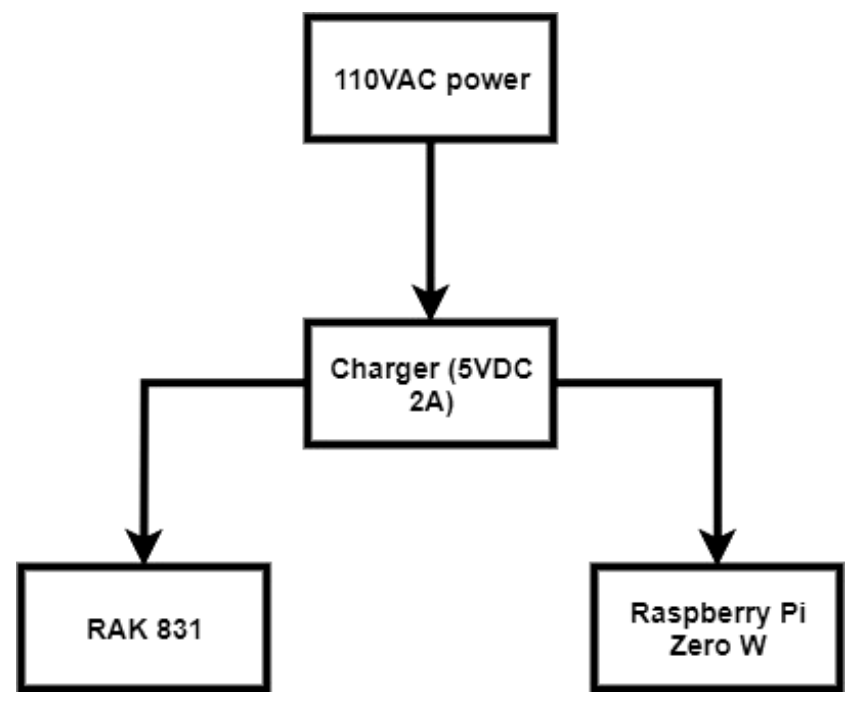

Fig. 4 Gateway Energization Diagram

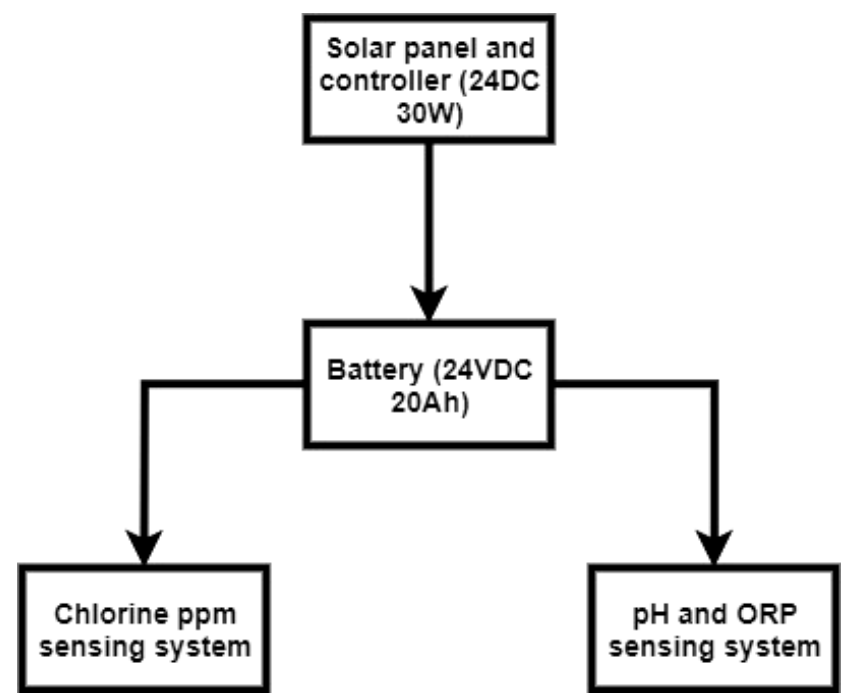

Fig. 5 Sensors Energization Diagram

E. Signal coverage area

To calculate the coverage area it was necessary to use Radio Mobile software in conjunction with Google Earth, in addition, it was necessary to use AirLink Ubiquiti to obtain more accurate results.

The study was done using the data of the $915 \mathrm{MHz}$ fiberglass antenna provided by the RAK 831 gateway kit, in addition to the maximum power values allowed for LoRa devices. The same data was used for the gateway and the node. The data were as follows:

TABLE II

CONFIGURATION DATA FOR GATEWAY AND NODE

\begin{tabular}{|c|c|}
\hline Item & Data/Value \\
\hline Antenna type & Omnidirectional \\
\hline Antenna gain & $6 \mathrm{dBi}$ \\
\hline Frequency & $915 \mathrm{MHz}$ \\
\hline Max TX power & $27 \mathrm{dBm}$ \\
\hline Tx line loss & $3 \mathrm{~dB}$ \\
\hline Rx line loss & $0.5 \mathrm{~dB}$ \\
\hline Rx threshold & $0.5 \mu \mathrm{V}$ \\
\hline
\end{tabular}

The process of studying the coverage area is described by the following diagram:

$18^{\text {th }}$ LACCEI International Multi-Conference for Engineering, Education, and Technology: "Engineering, Integration, 


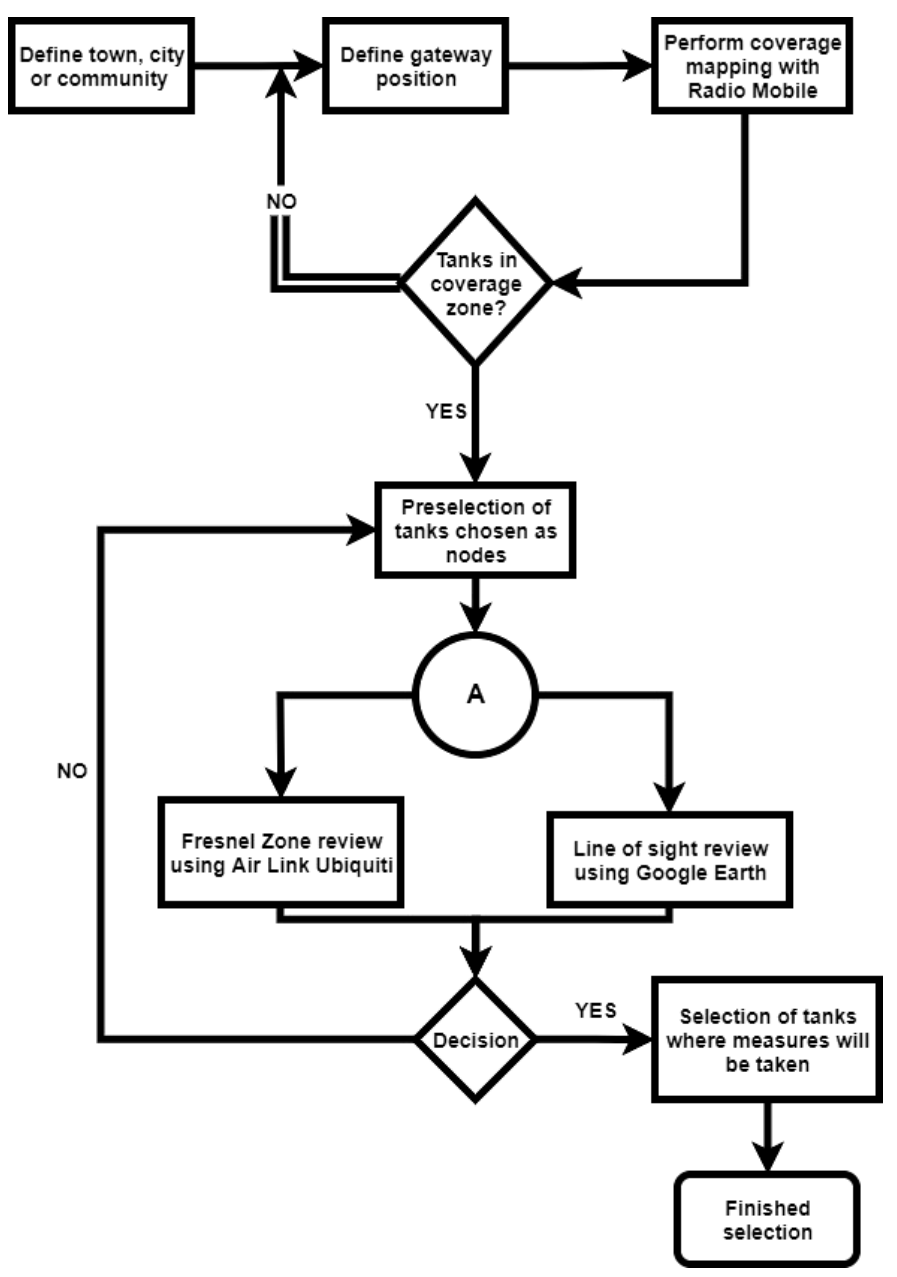

Fig. 6 Diagram of coverage area study

\section{F. Internet of Things (IOT) Implementation}

Data monitoring should be possible in real time, in order to provide follow-up and attention in a timely manner. It was necessary to program according to the data sent from the node to the gateway to be processed by an application, in this way, its visualization can be possible from a cell phone or computer with internet connection.

It was use The Things Network (TTN) application to display the messages, it was necessary to program a message decoder in Java in the TTN application portal. The last three steps of the diagram in Fig. 2 detail its process.

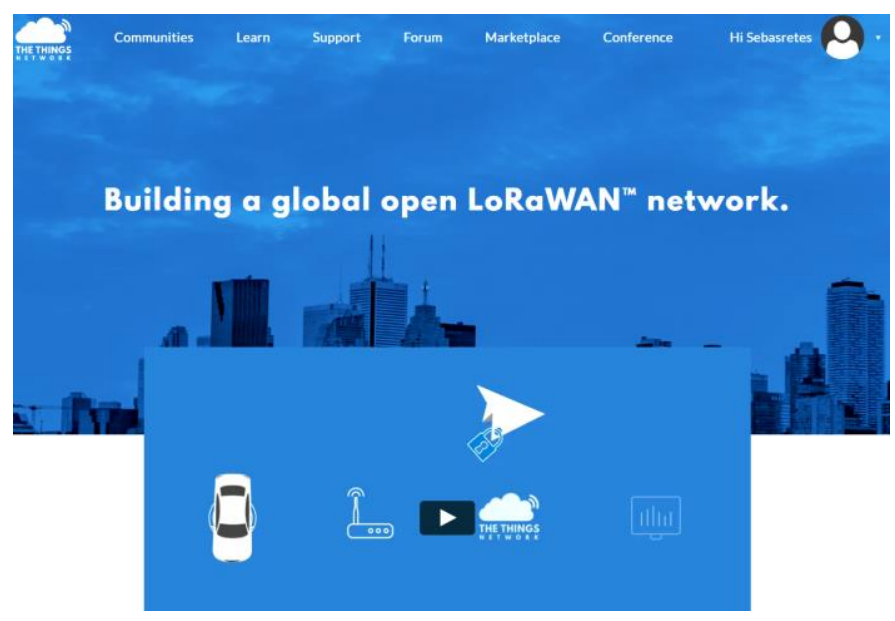

Fig. 7 TTN platform

The integration of InfluxDB was performed, which is a time series database server for storing the data received by TTN, in addition, Grafana was added, a tool to visualize time series data graphically. The organization of these two digital platforms has been achieved using Node-RED, it is a tool that served to communicate digital hardware and services. All this has been installed in one of the GNU / Linux distributions such as Kali Linux.

The sensor information sent to TTN was received by Node-RED with one of its nodes, the information was linked to an output node dedicated to InfluxDB, as shown in Fig. 8.

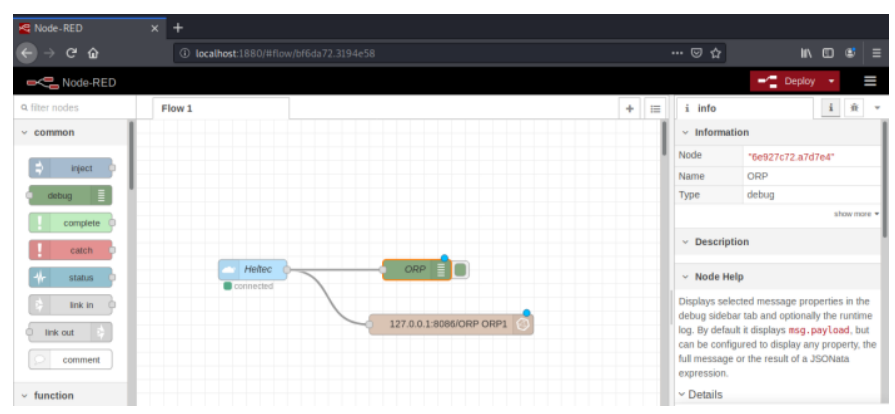

Fig. 8 Node-RED Configuration

InfluxDB stores the information as time series, these series are stored in the database within InfluxDB (see Fig. 9).

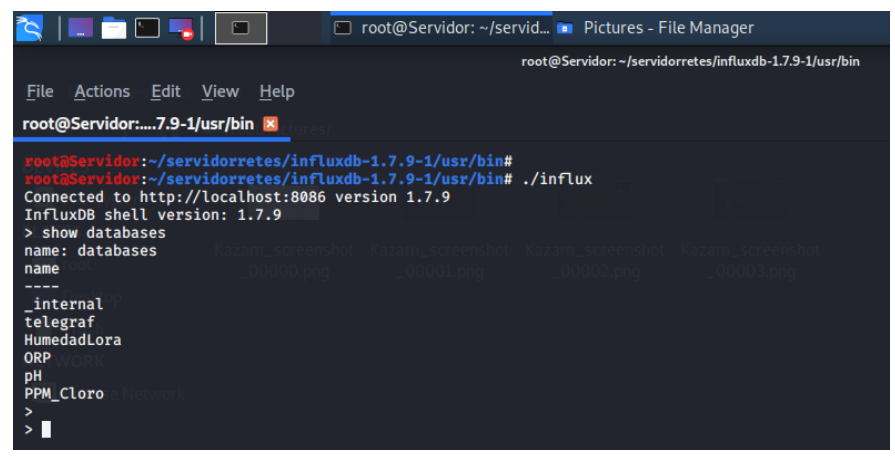

Fig. 9 InfluxDB database configuration

$18^{\text {th }}$ LACCEI International Multi-Conference for Engineering, Education, and Technology: "Engineering, Integration, And Alliances for A Sustainable Development”, 29-31 July 2020, Buenos Aires, Argentina. 
Subsequently, in Grafana, a data source dedicated to InfluxDB was added (see Fig. 10).

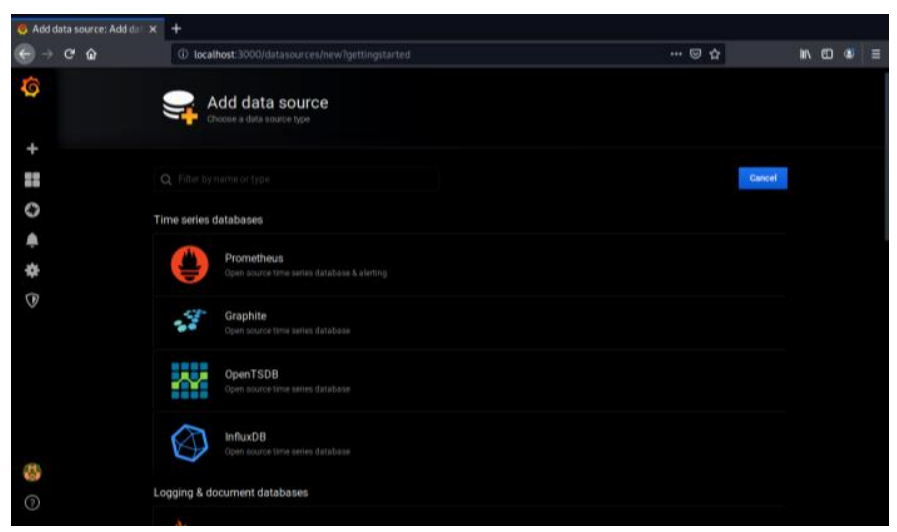

Fig. 10 Creation of a data source in Grafana

The data source was configured with the information and credentials (see Fig. 11).

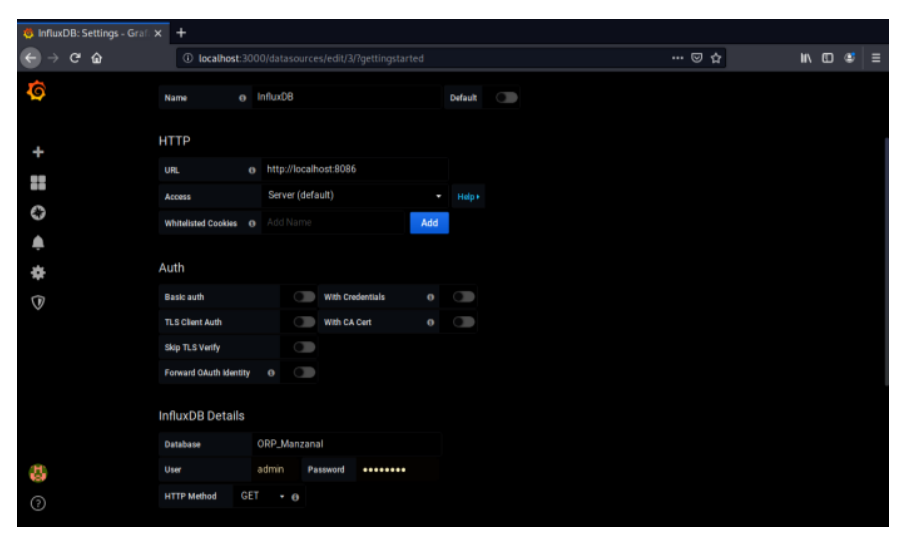

Fig. 11 Configuration parameters of data source in Grafana

\section{RESULTS}

\section{A. Communication system}

It was used LPWAN communication technology, with LoRaWAN and LoRa being the communication protocol and the physical layer respectively. The $915 \mathrm{MHz}$ band was used for all devices per CONATEL specifications.

It was used the RAK 831 module as a communication device and the Raspberry Pi Zero was the gateway controller as a gateway. These were chosen on top of already produced modules since their cost is lower, in addition it has the same functions, features and also having the possibility to modify its configuration as desired. In addition, eight communication channels are obtained, thus achieving the possibility of managing the communication of about 300 nodes at different frequencies within the range allowed by CONATEL.

It was installed the gateway in the latitude coordinate: $14^{\circ} 8^{\prime} 51.24^{\prime \prime} \mathrm{N}$; longitude coordinate: $88^{\circ} 2^{\prime} 36.96^{\prime \prime} \mathrm{W}$. This is a geographical position that has electricity and internet connection constantly.
In Fig.12 it shows the configuration of the gateway and its status in TTN.

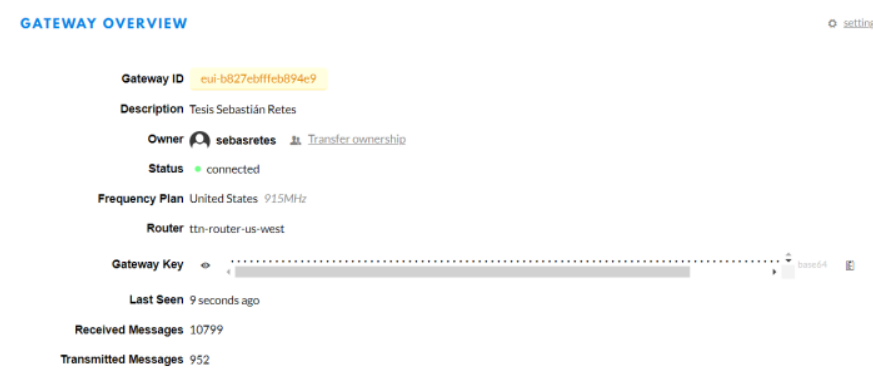

Fig. 12 Gateway connection

The reception of data was successful. In Fig. 13 it shows the traffic of incoming payloads in the receiving device.

$$
\begin{aligned}
& \text { GATEWAY TRAFFIC }
\end{aligned}
$$

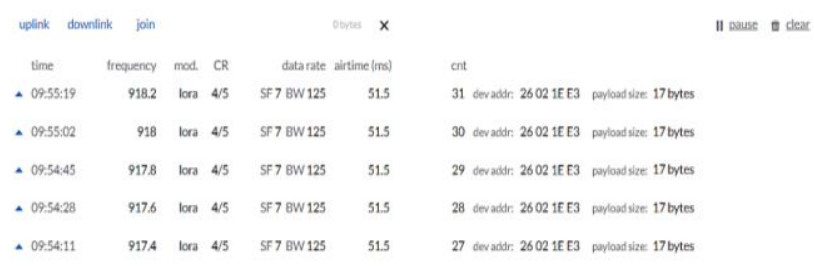

Fig. 13 Gateway data reception

\section{B. Energy consumption}

Table III shows the energy consumption resulting from the measurement systems and components of the system nodes, as well as the duration of the load of each of them.

TABLE III

RESULTS OF ENERGY CONSUMPTION

\begin{tabular}{|c|c|c|c|}
\hline Component & Assigned battery & $\begin{array}{c}\text { Battery } \\
\text { capacity }\end{array}$ & $\begin{array}{c}\text { Load } \\
\text { duration }\end{array}$ \\
\hline $\begin{array}{c}\text { Dragino Shield and } \\
\text { Arduino Uno }\end{array}$ & LiFePO4 6.6V & $800 \mathrm{mAh}$ & 1192 days \\
\hline $\begin{array}{c}\text { El Chiflador Sensors } \\
\text { node }\end{array}$ & Hykolity 24V & $20 \mathrm{Ah}$ & 86.4 hours \\
\hline $\begin{array}{c}\text { San Rafael Sensors } \\
\text { node }\end{array}$ & Hykolity 24V & $20 \mathrm{Ah}$ & 86.4 hours \\
\hline $\begin{array}{c}\text { El Manzanal Sensors } \\
\text { node }\end{array}$ & Hykolity 24V & $20 \mathrm{Ah}$ & 86.4 hours \\
\hline
\end{tabular}

There is a high level of autonomy in the Arduino Uno system with the Dragino Shield. In the monitoring module, specifically in the sensor system it was necessary to add a $24 \mathrm{~V}$ and $30 \mathrm{~W}$ solar power system in order to have sufficient autonomy of the monitoring module. In the case of the gateway energy consumption it is not relevant, since it is connected to a constant line of electricity through a $5 \mathrm{VDC}$ and $2 \mathrm{~A}$ power supply.

$18^{\text {th }}$ LACCEI International Multi-Conference for Engineering, Education, and Technology: "Engineering, Integration, 


\section{Signal coverage area}

With the Radio Mobile software and the technical data of the devices, an ideal coverage area for data transmission was achieved. The coverage area is indicated by the green areas shown in Fig. 14.

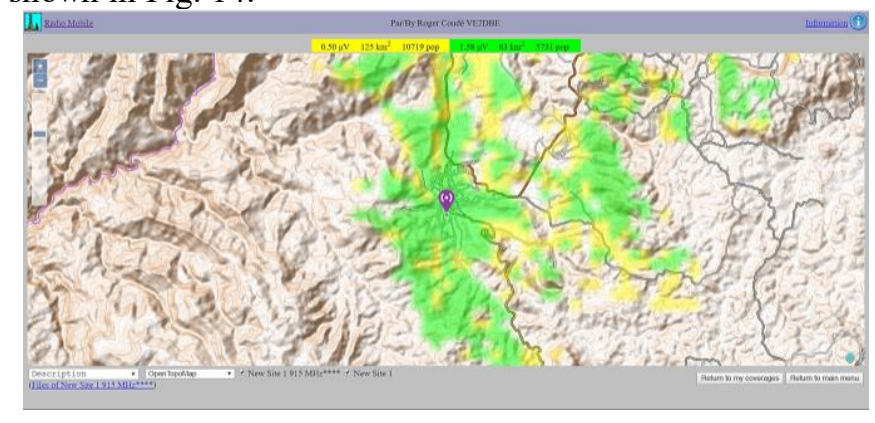

Fig. 14 Radio Mobile coverage area

The green and yellow areas are those that the gateway covers, it can be analysed that signal covers the entire urban area of the city of Marcala, La Paz and even its surroundings. The coverage map was exported to Google Earth to validate the positions of the nodes and see if they enter the gateway area, Fig. 15 shows the result.

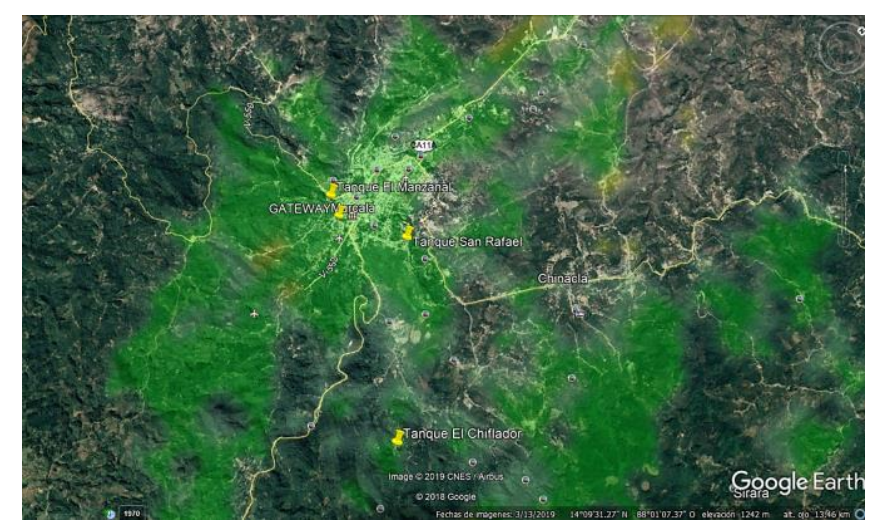

Fig. 15 Coverage zone in Google Earth

It can be observed the positions of the gateway and the storage tanks, resulting in the three storage tanks entering the coverage area perfectly and presenting excellent connection indicators.

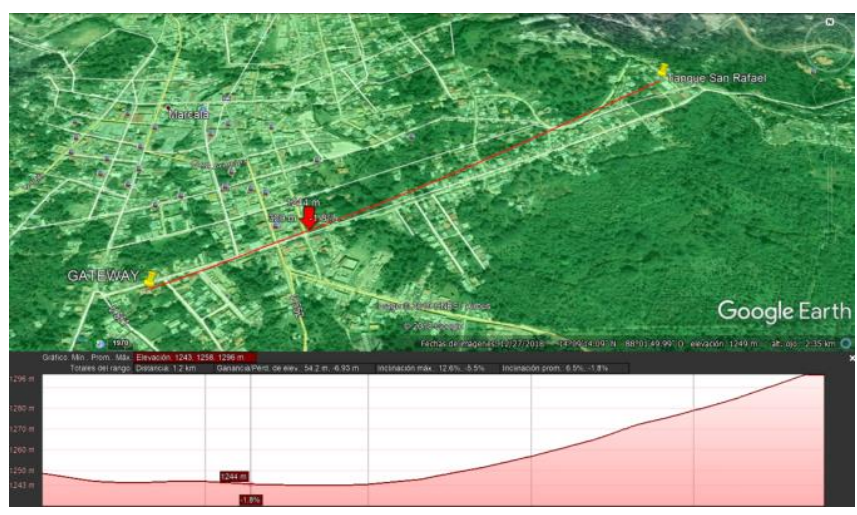

Fig. 16 San Rafael System line of sight

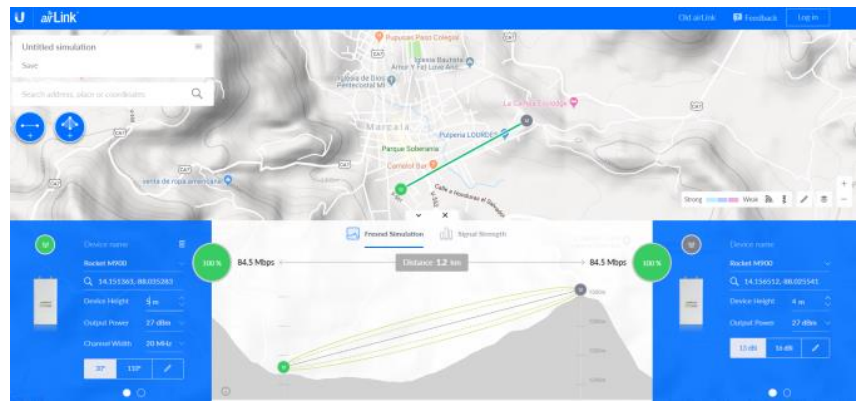

Fig. 17 San Rafael System Fresnel Zone

\section{IOT data display}

The visualization of the monitoring could be seen successfully on TTN, which showed that the programming of the decoding and sending of payloads were correct. In Fig. 18 the reading of ppm of residual chlorine, belonging to the storage tank system in El Chiflador, is observed.

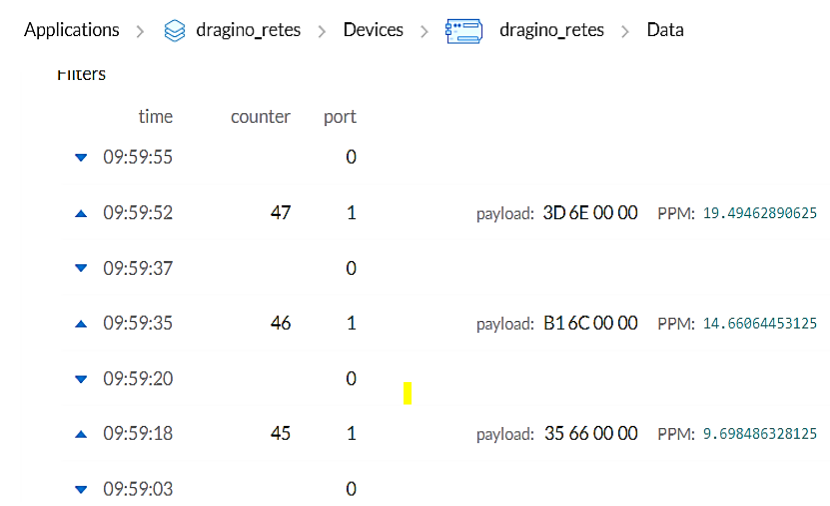

Fig. 18 Data visualization in storage tank in El Chiflador

In Fig. 19 the ORP and $\mathrm{pH}$ data belonging to the San Rafael and El Manzanal systems are shown. 
Applications > $\Leftrightarrow$ dragino_retes > Devices >

\section{APPLICATION DATA}

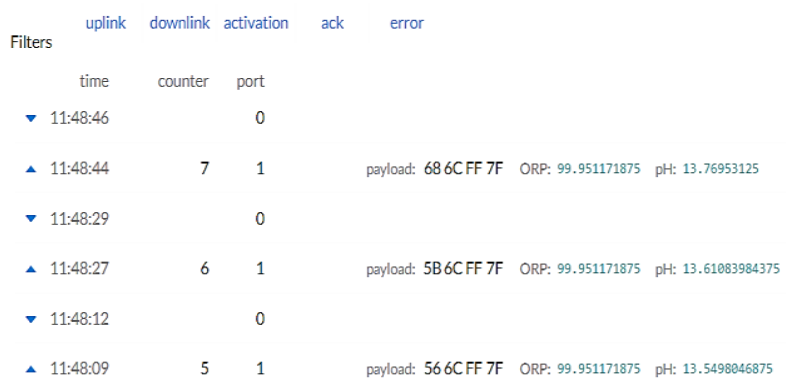

Fig. 19 Data visualization in San Rafael and El Manzanal tanks

Finally, it is possible to graphically visualize the data received by the sensors in the storage tanks of the different water purification systems through the Grafana platform. (See Fig 20).

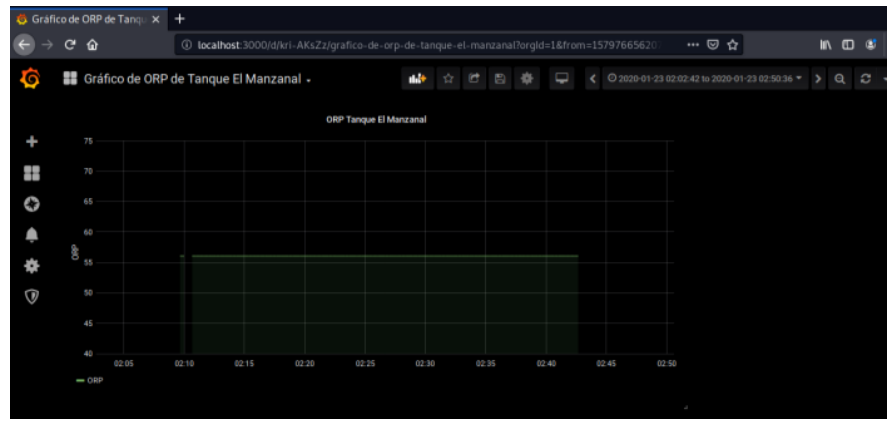

Fig. 20 Visualization of water parameters in storage tanks using the Grafana platform

\section{CONCLUSIONS}

It was possible to design and implement an intelligent system for monitoring and transmitting data of the most important parameters of water quality, implemented in drinking water treatment and storage systems for rural communities. The use of LPWAN technology and LoRa devices was indispensable for the realization of this project. The design turned out to be of low monetary cost, low energy consumption and an extensive coverage area, with it, it can be implemented with several nearby drinking water systems.

This intelligent system based on telecommunications and IOT technologies represents an innovative proposal to improve the management of water purification systems in rural areas, thereby boosting food security in developing countries.

\section{REFERENCES}

[1] Chaves Campos, A., Araya-Rodríguez, F., Chaves-Jiménez, A., \& YepezGarcía, V. (2005). Desarrollo de una red de monitoreo por sensores remotos de la calidad de agua. Tecnología en Marcha.
[2] Comisión Nacional de Telecomunicaciones (CONATEL) Honduras. (200, Abril 13). Reglamento de los sietmas de rediocomunicación que utilizan tecnología de Espectro Ensanchado. La Gaceta.

[3] Daigavane, V., \& Gaikwad, M. (2017). Water quality monitoring system based on IoT. Advances in Wireless and Mobile Communications, 11071116.

[4] Ente Regulador de los Servicios de Agua Potable y Saneamiento (ERSAPS). (2013). Diagnósticos Sectorales (a nivel de municipio). Obtenido de www.ersaps.hn: http://www.ersaps.hn/estudios.php

[5] Instituto Nacional de Estadistica (INE) Honduras. (2020). Instituto Nacional de Estadistica (INE) Honduras. Obtenido de www.ine.gob.hn: https://www.ine.gob.hn/V3/seccion/La-Paz/

[6] Ministerio de Salud (República de Honduras). (1995). Norma Técnica Nacional Para la Calidad del Agua Potable. Tegucigalpa, Honduras: Ministerio de Salud (República de Honduras).

[7] Moparthi, N., Mukesh, C., \& Sagar, P. (2018). Water quality monitoring system using IoT. Water quality moniInternational Conference on Advances in Electrical, Electronics, Information, Communication and Bio-Informatics (AEEICB) (pp. 1-5). IEEE.

[8] Organización Mundial de la Salud (OMS). (2009). Medición del Cloro Residual en el Agua. Organización Mundial de la Salud (OMS).

[9] Pavana, N., \& Padma, M. (2016, May). Design of low cost system for real time monitoring of water quality parameters in IoT environment. International Journal of Advance Research in Computer Science and Manegement Studies, pp. 12-15.

[10] The Things Network. (2019). The Things Network. Retrieved from www.thethingsnetwork.org: https://www.thethingsnetwork.org/forum/t/limitations-data-rate-packet-size30 -seconds-uplink-and-10-messages-downlink-per-day-fair-accesspolicy $/ 1300, \% 202019$

[11] UNICEF. (2017). Progresos en materia de agua potable, saneamiento e higiene: informe de actualización de 2017 y linea de base de los ODS. UNICEF.

[12] Vijayakumar, N., \& Ramya, A. (2015). The real time monitoring of water quality in IoT environment. International Conference on Innovations in Information, Embedded and Communication Systems (ICIIECS) (págs. 15). USA: IEEE.

[13] World Health Organization (WHO). (1971). International standards for drinking-water. Geneva, Switzerland: World Health Organization (WHO).

$1^{\text {th }}$ LACCEI International Multi-Conference for Engineering, Education, and Technology: "Engineering, Integration, 